\section{Going on the defensive}

\author{
Constraints on the UK chemical industry are affecting \\ research in its laboratories. John Manos describes how
}

\begin{abstract}
THE chemical industry has suffered
some nasty shocks in recent years.

The basic economics of oil-based petrochemicals production has been severely shaken by rises in the oil price, while in other sectors the industry has had to face the onslaught of environ-
\end{abstract} mentalists and regulators.

Because the industry is more research-based than most, it is not surprising that these pressures should have had their effect in directing work in its laboratories. But they are not the only factors which have contributed to a major shift in research aims. In general, a growing maturity in the private industry's end products together with the above constraints (and the economic pressures of a recession) have meant that research effort is increasingly described as 'defensive', allowing companies to maintain their existing positions in the face of controls and inflation, while consolidating their expertise in established product areas.

Research is increasingly devoted to 'replacement' ventures, in which old processes, extravagant on energy and raw materials, are replaced by new processes economical in both. By applying a total design or total systems concept, the industry is re-training itself to satisfy this new long-range research aim. Also the paucity of totally new products which have provided a satisfactory return over the decade, has meant that less and less effort is devoted to 'blue sky' research and the research function is having to gear itself to satisfy more of private industry's short-term aims. That means fewer new drugs and pesticides and no really new plastics.

This applies to both those polymer products which showed spectacular growth over the past twenty years and to the higher value fine chemicals, drugs and agrochemicals whose development is more readily associated with broadly-based laboratory research aims. In both these areas less than $10 \%$ of research effort is now spent on the search for new products, the increasingly competitive nature of the business now requiring that $90 \%$ be spent on improvement and widening the range of products and on reducing costs.

The bulk petrochemicals industry, which has allowed the rapid growth of polymer production to take place, has reached a different sort of maturity. The petrochemicals industry believes that Europe should have an energy policy that preserves for the chemical industry the chemical structures in $5 \%$ of total oil production, oil being too valuable to burn. If governments behave foolishly, the industry in Europe is considering which raw materials will replace (and to what extent) the cheap naphtha refinery byproduct on which it has grown up. Research here is economic analysis of how best new feedstocks can fit in with established downstream production. While governments and state industries look at (or talk of) long term possibilities for the exploitation of new bulk raw materials, such as associated gas from North Sea oil wells or even coal, private companies are preoccupied with justifying the operation of their existing facilities.

\section{Biochemical engineering}

If there is a pattern characterising research trends that is not symptomatic of the search for energy economy, pollution-free processes, or quickly exploitable product refinements, it is the opening up of entirely new areas of business based on the extension of chemistry into biology, and chemical engineering into biochemical engineering. It is surprising, for example, that each of the UK's big three chemical companies (and one of West Germany's) should have devoted such great research effort in seeking to move into the animal feedstuff industry. Yet this illustrates one of the chief areas of diversification: biochemical engineering.

In commercialising their bioproteins (or single cell protein) processes, BP, ICI and Germany's Hoechst are entering into a commodity business which is less well-known to them. In fact it is uncertainty about future price trends of the natural products which they aim partly to replace-soya bean and fish meal-which the third UK company, Shell, cites as the reason for its withdrawal from the development race. Nevertheless, $20 \%$ of ICI's 1977 capital investment sanctioning is devoted to a 50-75,000-ton-per-year plant to produce pig and poultry feed from hydrocarbon (methanol) feedstock. Methanol is also used in another animal feed development of ICI's at Billingham.

The bioproteins development programme has cost ICI $£ 10$ million over the past eight years with half spent in the last three. In its 1977 report, ICI

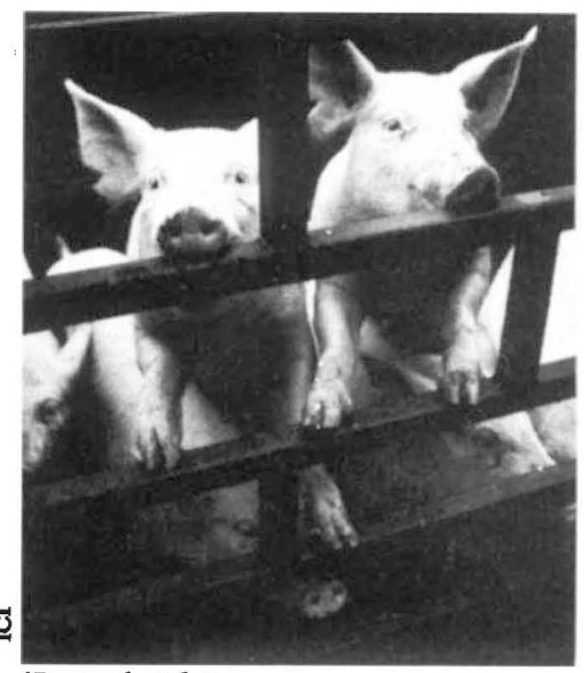

'Pruteen' piglets

describes this as a result of its 1960s initiative in applying process engineering know-how to microbiology. It is part of a bio-sciences research policy which the company has increasingly pursued in cooperation with universities. Other products of this line of research include processes for the continuous production of enzymes for the food industry (particularly isomerase for the production of high fructose corn syrup, for which ICI is now building a US manufacturing plant) and ICI's 'deep shaft' waste water treatment process which uses a mildly pressurised biochemical reaction to accelerate the conventional treatment process.

The forces which have encouraged the majors to venture into such unknown areas are the same as those which make research management in existing areas of business so difficult: the need for speedy explaitation of new developments countered by the increasingly long lead times to get new chemical products on the market. This latter point has been well documented for the agrochemicals industry where resources required to carry new insecticide through its seven- to nineyear path of screening, toxicology, field trials, registration and marketing are such as to restrict innovatory development to only a small number of major companies.

\section{Development efiort}

The development effort has swung over to what are generally less toxic products such as herbicides, or to the development of more efficient methods of applying existing compounds: ultrafine sprays, slow release and encapsulated insecticides. Also newer synthetic pyrethroids under development are safer than the organophosphorous and carbamate products which are themselves safer than the organochlorines (which include DDT, aldrin and dieldrin). 
Plant design and construction has been one area where companies have attempted to shorten development time. Shell Chemical, for example, has invested $\$ 19$ million in a flexible agrochemicals production facility at Pernis, Rotterdam, which, although initially dedicated to specific products, incorporates in its design a service and equipment flexibility which will allow a switch to production of another product in as little as two months. But Shell still regards agrochemical development as a high-risk area from which resources will be diverted to more profitable business unless the regulatory pressures are eased.

The need to accelerate the worldwide exploitation of new developments is cited as one of the reasons why the overseas research budget of ICI has increased in recent years (from 25$30 \%$ of total in 1976). Thus, in the USA, ICI has extended its pharmaceuticals research effort so as to have the advantage of a scientific dialogue across the North Atlantic; and in India it is hoping to set up some central research facilities that will better use indigenous Indian raw materials within the Indian economy.

In general, however, rationalisation means centralisation, as illustrated by Hoechst and Shell's plans for their research facilities in Europe, although ICI still believes in a great deal of autonomy for its separate major business area. The greater part of Hoechst's investment in research facilities in recent years has been in its new multidisciplinary centre being built up in Frankfurt, which the company feels is necessary to cope with the rapidly changing demands of the market and of raw material supplies. Similarly last year Shell completed the transfer of all chemicals and polymers research facilities outside North America (except for agricultural pro-

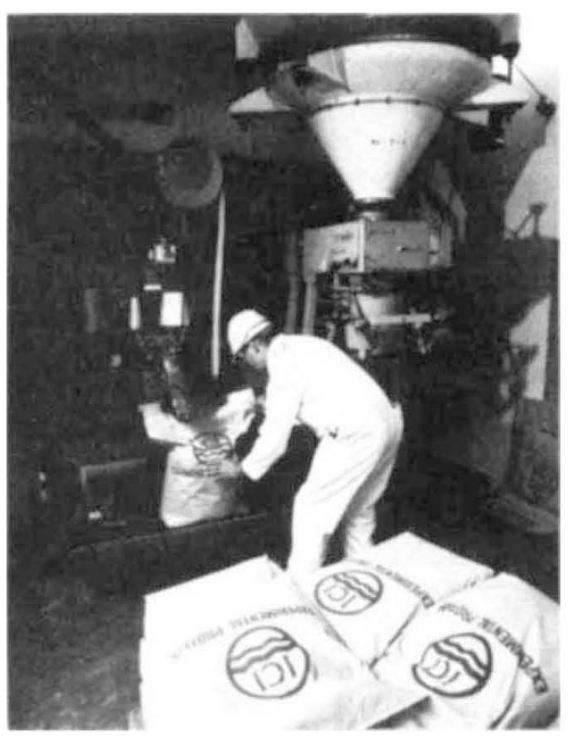

Protein pilot plant ducts) to one site in Amsterdam.

As with agrochemicals, polymer research trends have been greatly influenced by the need to consolidate positions of strength and refine the properties of mature products. Hoechst notes that of the twelve plastics which represent $90 \%$ of Germany's consumption, not one has been developed within the last ten years. Polypropylene is the fastest growing new bulk plastic which threatens to compete strongly with the ethylene-based polyethylene, PVC and polystyrene (which account for $80 \%$ of German consumption) but this good rate of growth has come after twenty years of development! Other unique new materials such as carbon fibre, the wonder material of the sixties, have been overtaken by existing polymer technology which can satisfy rapidly changing customer demands more quickly and cheaply. The day of the accidentally-produced polymer having a market developed for it have passed.

The same accent on the selective development of established products was echoed by Shell last year in opening its polymer research centre in Amsterdam. It was suggested that the company, which had already withdrawn from two polymer areas (general-purpose rubber in the USA and high density polyethylene in the UK), might withdraw from other areas if its position was not strong. Certainly some polymer areas have shown a poor profitability recently. But as a number of products reach maturity over the next few years, Shell hopes that the concentration of product-oriented research capability at Amsterdam will allow a broadening of the range of applicability while process research is directed towards the development of improved, or secondgeneration processes for the production of the same polymers.

\section{Non-productive research}

Perhaps the most rapidly growing research area, however, is that involving non-productive work associated with toxicology and the control and detection of carcinogens. The complaints about over-regulation now heard from the agrochemical sector come more than a decade after the first problems associated with the use of agricultural chemicals caught the public eye. It was in the 1950s that concern over such products as the insecticide DNOC (dinitrocresol), which had caused the deaths of four farm workers, resulted in the setting up of the UK's Pesticide Safety Precaution Scheme. But increasingly stringent screening and animal testing techniques have always played a major part in product development in the agrochemical and the pharmaceutical industry. Exposure limits and precautions for use of other chemicals not in contact with people or vegetation have generally been retrospective, based on experience of the chemicals in use.

This will not be so in the future. The 'ecology movement' and the need to avoid the difficult problem of dealing with a widely-used and manufactured product which is subsequently found to be dangerous and/or persistent in the environment will mean far tighter control on the introduction of all new chemical products. The US industry is already grappling with the massive requirements of the Toxic Substances Control Act and similar legislation is presently being formulated in Europe.

One of the biggest problems is the control of cancer-causing substances, or those which have given indication that they might be carcinogenic. The furore created by the US Food and Drug Administration's recent restrictions on the use of the sweetener saccharin and plastic sofit drink bottles containing acrylonitrile indicates, according to the more pragmatic European view, the disadvantage of adopting a strict legalistic approach to the problem. But whatever the control strategy employed with known carcinogens, the problem remains simply how to screen new products for carcinogenicity to avoid the problem arising. With the several thousand new chemical products introduced every year being required to satisfy this sort of criterion, there is an urgent need for a simpler, quicker and cheaper screening procedure in preference to the conventional lengthy animal studies.

One of several possibly applicable in vitro tests is the Ames test, developed in the USA, which uses the mutation of bacteria strains as an indication of possible carcinogenic potential. For US companies such as Dow Chemical, currently spending $15 \%$ of its R\&D budget on toxicology, such developments are of major importance in the light of new legislative requirements. But in Europe, too, in vitro testing is a major research area: ICI's central toxicology research laboratories have further developed the Ames test (in combination with another test involving mammalian cell transformation) to give the most reliable in vitro indication of carcinogenicity yet developed.

This exciting project is already justifying a budget of $£ 250,000$ a year which will rise to about $£ 750,000$ a year by 1978-9. Through such techniques, the company also sees a possible resolution of the problem of establishing no-effect levels for exposure to carcinogens, possibly within five years, 